ANNALES

UNIVERSITATIS MARIAE CURIE-SKŁODOWSKA LUBLIN - POLONIA

VOL. LXXI, 2

SECTIO AA

2016

\title{
Adsorption Potential Theory for description of n-butane adsorption on activated carbon
}

\author{
Mieczysław Bałys ${ }^{\mathrm{a}}$, Jakub Szczurowski ${ }^{\mathrm{a}}$, Leszek Czepirski ${ }^{\mathrm{b}^{*}}$ \\ and Marek Kochel ${ }^{\mathrm{b}}$ \\ ${ }^{a}$ AGH - University of Science and Technology, Faculty of Energy \\ and Fuels, Department of Coal Chemistry and Environmental Sciences, \\ Al. Mickiewicza 30, 30-059 Kraków, Poland \\ ${ }^{b}$ ABC-Z System Eko, Przemystowa Str. 10, 40-020 Katowice, Poland \\ "email: czepir@agh.edu.pl
}

Potential theory of adsorption was used for description of adsorption isotherms of n-butane on microporous active carbon. It was shown that characteristic curve of adsorption can be treated as specific form of thermal equation of adsorption giving the possibility to calculate and predict both equilibrium and thermodynamic characteristics of adsorption in wide range of temperature and relative pressure. The results can be used for the design of adsorption systems and for predicting adsorption equilibrium behavior of binary and/or multicomponent gaseous mixtures on active carbon under wide range of conditions, without time consuming and expensive experimental determination.

\section{INTRODUCTION}

Nanoporous activated carbons are carbonaceous materials with extended surface area, well-developed microporosity, and high degree of surface reactivity [1-2]. For these reasons they has been used extensively as an adsorbent in a variety of fields such as air pollution control [3], gas purification and separation, solvent recovery, natural gas and hydrogen 
storage [4-5]. Important applications relate to the use of activated carbons ability to remove a large variety of compounds from contaminated waters. They find application in areas such as wastewater treatment, water purification, discoloration, and removal of toxic organics, and heavy metals ions [6-7].

Carbonaceous adsorbents are also utilized in both field and industrial processes such as adsorption refrigeration and air-conditioning [8].

Highly-porous carbon materials have demonstrated to be ideal candidates as electrode material in supercapacitors due to their high surface area, good electronic conductivity and high electrochemical stability, relatively low cost and availability [9].

All of the above mentioned applications need the knowledge of adsorption equilibria, as well as thermodynamic properties of adsorbent - adsorbate system. One of the most widely used theories for correlating adsorption equilibria onto microporous adsorbents was introduced by Polanyi (1914) and next developed by Dubinin, and is generally referred to as the adsorption potential theory. Although this theory is considered a semiempirical approach, it has achieved great success in many practical applications.

In this work we report the pure-component equilibrium data for adsorption of n-butane at different temperatures on the nanoporous activated carbon. The hypothesis that these data could be represented by the potential theory of adsorption was tested and isosteric enthalpy of adsorption was determined.

\section{SUPPORTING THEORY}

The adsorption potential theory introduced by Polanyi (1914) [10] assumes that the adsorption forces act at longer distances than the molecule size and are not screened by the first layer of adsorbed molecules. The adsorption layer has a diffusive character and its density changes with the distance from the surface. Polanyi's model, consider a series of equipotentials on the surface of the solid, adsorbate molecules are placed on these surfaces, which are assumed in as quasi-liquid in a force field known as the adsorption potential field, thus defining a space or volume between these surfaces and the solid surface.

The potential theory of adsorption correlates two parameters: $W-$ the volume of adsorbed phase and $\varepsilon$ - the adsorption potential: 


$$
W=a \cdot V_{m}=F(\varepsilon)
$$

where:

$a$ - equilibrium amount of gas adsorbed,

$V_{m}$ - the molar volume of the adsorbed phase,

$F$ - the characteristic adsorption function,

The adsorption potential characterizes the difference in free energy between the adsorbed phase and the saturated liquid adsorbate and is defined as:

$$
\varepsilon=-R T \cdot \ln \left(\frac{p}{p_{s}}\right)
$$

where $p$ is the equilibrium pressure at temperature $T, p_{s}$ is the saturated vapor pressure of the adsorbate, and $R$ is the ideal gas constant.

According to Polanyi the adsorption potential in a given temperature range is irrespective of the temperature, thus:

$$
\begin{gathered}
\left(\frac{\partial \varepsilon}{\partial T}\right)_{V_{m}}=0 \\
\varepsilon=-R T_{1} \cdot \ln \left(\frac{p_{1}}{p_{s, 1}}\right)=-R T_{2} \cdot \ln \left(\frac{p_{2}}{p_{s, 2}}\right)
\end{gathered}
$$

Adsorption potential theory does not yield a define adsorption isotherm, but gives the so-called characteristic adsorption curve, and the relation (1) is a characteristic adsorption function.

Since the characteristic curve is temperature independent, only adsorption equilibrium measurements at one temperature are needed to obtain the characteristic curve, and this should be sufficient to describe the adsorption at all temperatures for the same adsorbent-adsorbate system.

This theory can be generalized by introducing the affinity (similarity) coefficient $(\beta)$ which is used as shifting factor to bring the characteristic curves of different adsorbates on the same adsorbent into a single curve:

$$
\frac{\varepsilon_{1}}{\beta_{1}}=\frac{\varepsilon_{2}}{\beta_{2}}=\ldots \ldots \ldots . .=\frac{\varepsilon_{n}}{\beta_{n}}
$$


Under this assumption Eq. (1) can be replaced by:

$$
W=F\left(\frac{\varepsilon}{\beta}\right)
$$

According to Dubinin the purpose of using an affinity coefficient $(\beta)$ is that all characteristic curves for various adsorbates on a given adsorbent at different temperatures are superimposable on single reduced characteristic curve.

Much works have been realized on the estimation of the affinity coefficient and of particular importance is Wood's [11] who has published an extensive compilation of $\beta$ values for gases and vapors on activated carbon. According to this work $\beta$ is highly correlated to the molecular parachor $\left(P_{m}\right)$ of adsorbate:

$$
\beta=8,27 \cdot 10^{-3} \cdot P_{m}^{0,9}
$$

and this approach we used in our study.

Based on the Polanyi's approach, Dubinin and Radushkevich [12-13] developed theory where filling the micropore volume is the fundamental concept that is associated to a limit value of adsorption and this in turn is related to the coefficient of thermal expansion adsorbate.

They stated that the characteristic adsorption curve was correlated to the porous structure of the adsorbent. The attempt was made to justify theoretically the characteristic curves for the microporous adsorbent. There was proposed an equation, which was called the equation of Dubinin-Radushkevich (DR) adsorption isotherm and can be used to calculate the volume of liquid adsorbate in micropores:

$$
W=W_{o} \exp \left[-\left(\frac{\varepsilon}{\beta E}\right)^{2}\right]
$$

where: $W_{o}$ is the so-called limiting volume at the potential $\varepsilon=0$, approximately equal to the volume of the micropores, and $E$ is characteristic adsorption energy.

Adsorption phenomena are accompanied by heat evolution and therefore the knowledge of thermodynamic characteristics is key for analysis of given adsorben-adsorbate system. Although many different types of enthalpy of adsorption have been defined, the differential isosteric enthalpy of adsorption is found to be the most useful for 
adsorption practice. For the models having thermodynamic basis the application of Clausius-Clapeyron relation makes it possible to derive the equation describing the isosteric sorption enthalpy [14-15]:

$$
q^{s t}=\frac{R T^{2}}{p_{s}} \frac{d p_{s}}{d T}+\varepsilon-\alpha T\left(\frac{\partial \varepsilon}{\partial \ln a}\right)_{T}
$$

Equation (9) is the resulting $q^{\text {st }}$ equation that will be used with the experimental data. However, the values of $\alpha$ and $d p_{s} / d T$ need to be evaluated. In this work volumetric thermal expansion coefficient of adsorbate $(\alpha)$ was calculated from adsorbate densities at normal boiling point temperature $\left(\rho_{n b p}\right)$ and critical temperature $\left(\rho_{c}\right)$ :

$$
\alpha=\frac{1}{T_{c}-T_{n b p}} \ln \left(\frac{\rho_{n b p}}{\rho_{c}}\right)
$$

The derivative $d p_{s} / d T$ was obtained from Antoine relationship between saturated vapor pressure and temperature.

\section{EXPERIMENTAL}

The adsorbent used in this study was EcoSorb ${ }^{\circledR}$ BX-Plus extruded coal based activated carbon (Jacobi Carbons Group). The textural properties of the sample were determined using physical adsorption of $\mathrm{N}_{2}$ at $77 \mathrm{~K}$ using a Quantachrome Autosorb 1C analyzer. The parameters obtained are:

- BET surface area $\left(S_{B E T}\right)$,

- total pore volume at $p / p_{s}=0.99\left(V_{t}\right)$,

- micropore volume $\left(V_{m i}\right)$ determined by applying the DubininRadushkevich (DR) equation,

- surface area of micropores $\left(S_{m i}\right)$,

- half pore width of micropores $(x)$,

- mesopore volume $\left(V_{m e}\right)$ determined from desorption branch of isotherm using BJH method,

- surface area of mesopores $\left(S_{m e}\right)$,

- mesopores radius $\left(r_{m e}\right)$,

and they are listed in Table 1. 
BET method was applied only in the range of relative pressures between 0.001 and 0.2 , for which linearity could be observed. It was also found that the $\mathrm{N}_{2}$ adsorption in the relative pressure range $0.00001 \div 0.01$ can be described by a unique DR linear region.

The pore size distribution (PSD) of the activated carbon was calculated from nitrogen adsorption isotherms using SAIEUS software (Micromeritics) [16]. We used 2D-NLDFT model for carbons with heterogeneous surfaces. Fig. 1 presents bimodal shape of the pore size distribution (PSD) curve which is typical for various carbonaceous materials.

Table 1. Characteristics of porous texture for activated carbon determined from $\mathrm{N}_{2}$ adsorption isotherm at $77 \mathrm{~K}$.

\begin{tabular}{cccccccc}
\hline $\begin{array}{c}S_{B E T} \\
{\left[\mathrm{~m}^{2} / \mathrm{g}\right]}\end{array}$ & $\begin{array}{c}V_{t} \\
{\left[\mathrm{~cm}^{3} / \mathrm{g}\right]}\end{array}$ & $\begin{array}{c}V_{m i} \\
{\left[\mathrm{~cm}^{3} / \mathrm{g}\right]}\end{array}$ & $\begin{array}{c}S_{m i} \\
{\left[\mathrm{~m}^{2} / \mathrm{g}\right]}\end{array}$ & $\begin{array}{c}x \\
{[\mathrm{~nm}]}\end{array}$ & $\begin{array}{c}V_{m e} \\
{\left[\mathrm{~cm}^{3} / \mathrm{g}\right]}\end{array}$ & $\begin{array}{c}S_{m e} \\
{\left[\mathrm{~m}^{2} / \mathrm{g}\right]}\end{array}$ & $\begin{array}{c}r_{m e} \\
{[\mathrm{~nm}]}\end{array}$ \\
\hline 1290 & 0.764 & 0.499 & 1405 & 0.76 & 0.164 & 112 & 1.68
\end{tabular}

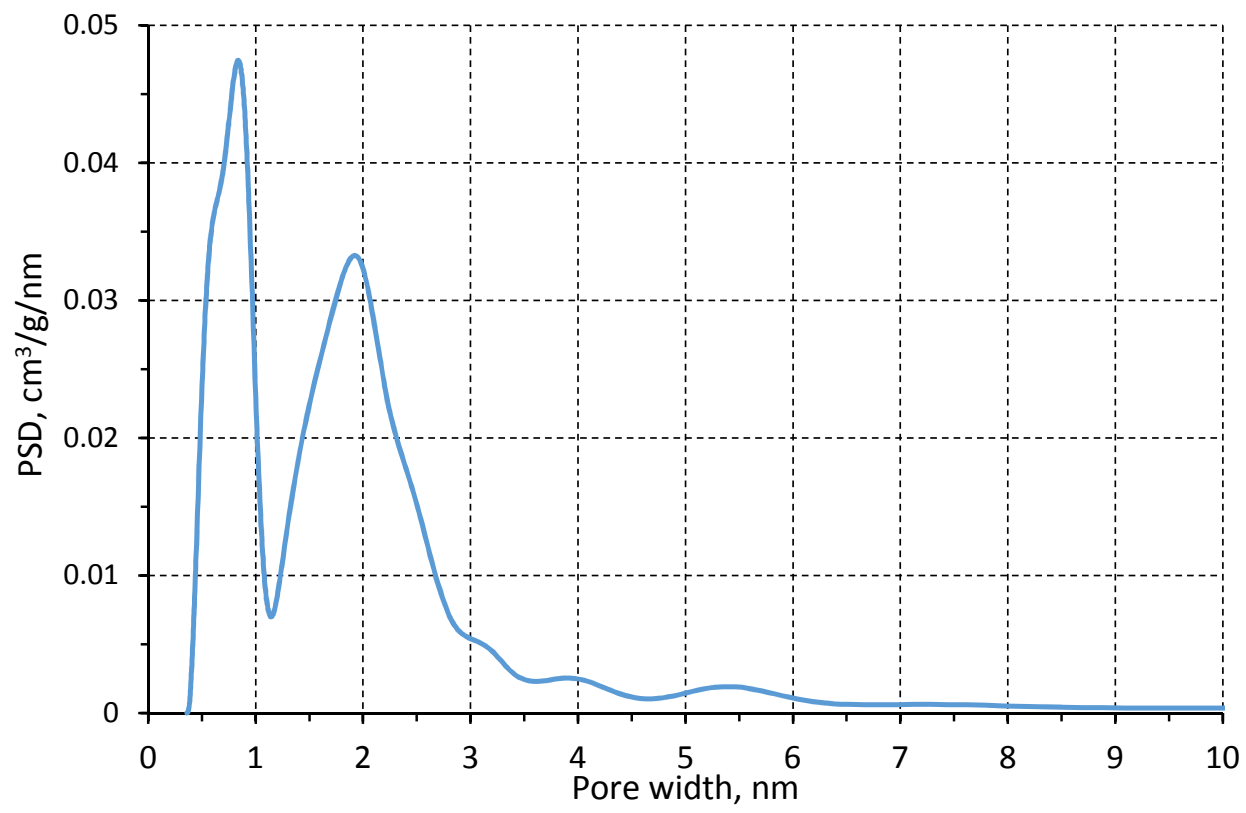

Fig. 1. Pore size distributions calculated for EcoSorb ${ }^{\circledR}$ BX-Plus activated carbon. 
Butane adsorption isotherms in temperature range 273-314K were also determined using Autosorb 1C analyzer.

\section{RESULTS AND DISCUSSION}

Experimental adsorption isotherms of n-butane at $273 \mathrm{~K}, 294 \mathrm{~K}$ and 314K, for a pressure up to $100 \mathrm{kPa}$ are shown in Fig. 2.

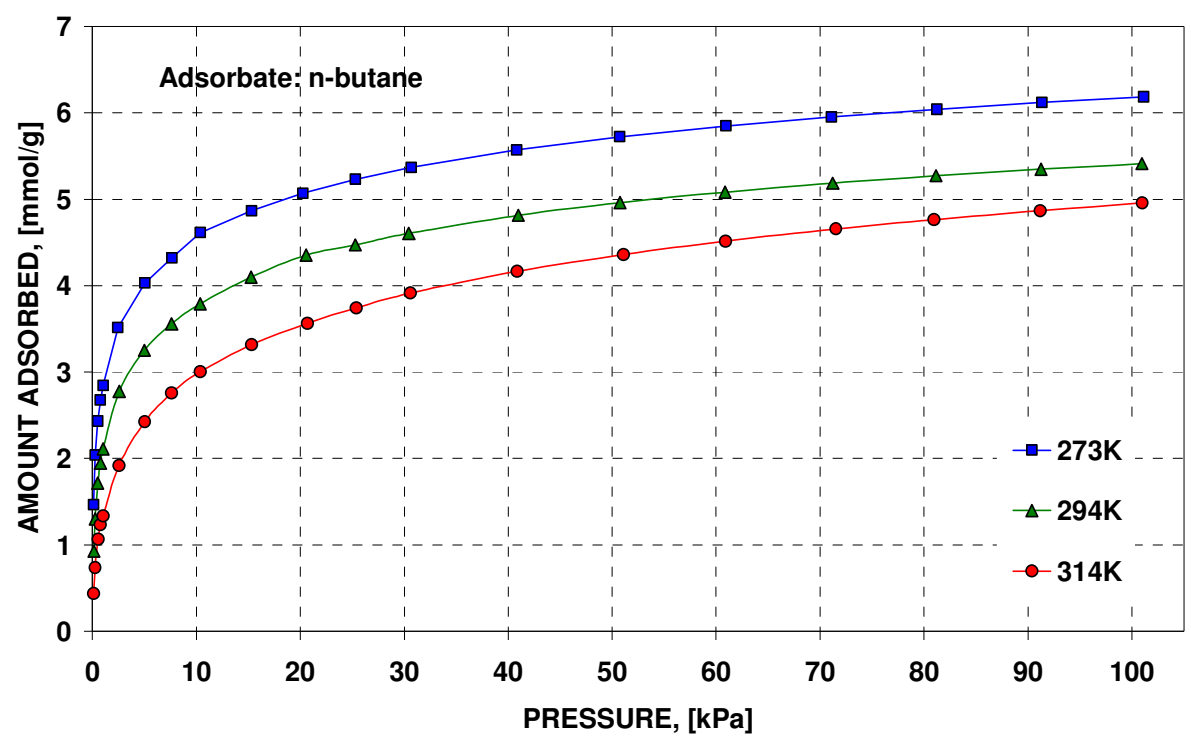

Fig. 2. Butane adsorption isotherms on activated carbon under study.

They are found to have a Type I shape according to the IUPAC classification and are typical for microporous activated carbons. Adsorption isotherms of n-butane at $273 \mathrm{~K}, 294 \mathrm{~K}, 314 \mathrm{~K}$ and nitrogen at $77 \mathrm{~K}$ were next correlated by plotting the logarithm of the volume adsorbed vs. the square of the reduced adsorption potential $(\varepsilon / \beta)$ and obtained generalized characteristic curve is presented in Fig. 3.

It can be seen that butane characteristic curve is temperature independent and in micropore region superimposes on nitrogen characteristic curve. This allows us to conclude that in this region butane adsorption provides similar information as low temperature nitrogen adsorption. Therefore, experimental butane adsorption isotherms were also interpreted by the use of the Dubinin - Radushkevich equation. Table 2 contains parameters of microporous structure of active carbons under 
study obtained from butane isotherms and low temperature nitrogen isotherm.

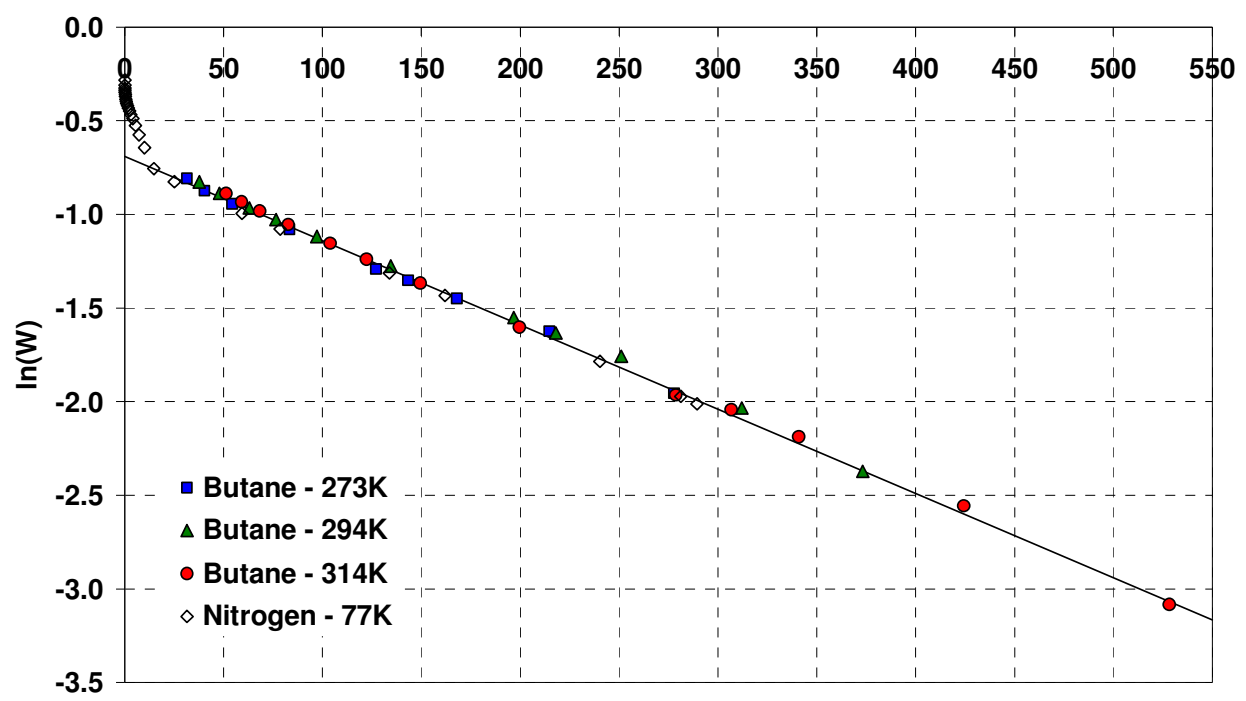

REDUCED ADSORPTION POTENTIAL, [kJ/mol]

Fig. 3. Generalized characteristic curve for active carbon under study.

Table 2. Parameters of microporous structure of activated carbon calculated from DR equation.

\begin{tabular}{cccc}
\hline \multicolumn{2}{c}{ Butane } & \multicolumn{2}{c}{ Nitrogen } \\
\hline $\begin{array}{c}W_{o} \\
{\left[\mathrm{~cm}^{3} / \mathrm{g}\right]}\end{array}$ & $\begin{array}{c}E \\
{[\mathrm{~kJ} / \mathrm{mol}]}\end{array}$ & $\begin{array}{c}W_{o} \\
{\left[\mathrm{~cm}^{3} / \mathrm{g}\right]}\end{array}$ & $\begin{array}{c}E \\
{[\mathrm{~kJ} / \mathrm{mol}]}\end{array}$ \\
\hline 0.507 & 14.88 & 0.500 & 14.92 \\
\hline
\end{tabular}

The results demonstrate that the approach proposed gives the possibility to analyse the microporous structure of carbonaceous adsorbents because butane kinetic diameter is enough to be accessible to the micropores of smaller size.

Next, the energy released in the adsorption process was analyzed. The isosteric enthalpy of adsorption $\left(q_{s t}\right)$ was calculated from Eq. 9. The run of adsorption enthalpy (Fig. 4) shows adsorption heterogeneity associated with activated carbon texture. 


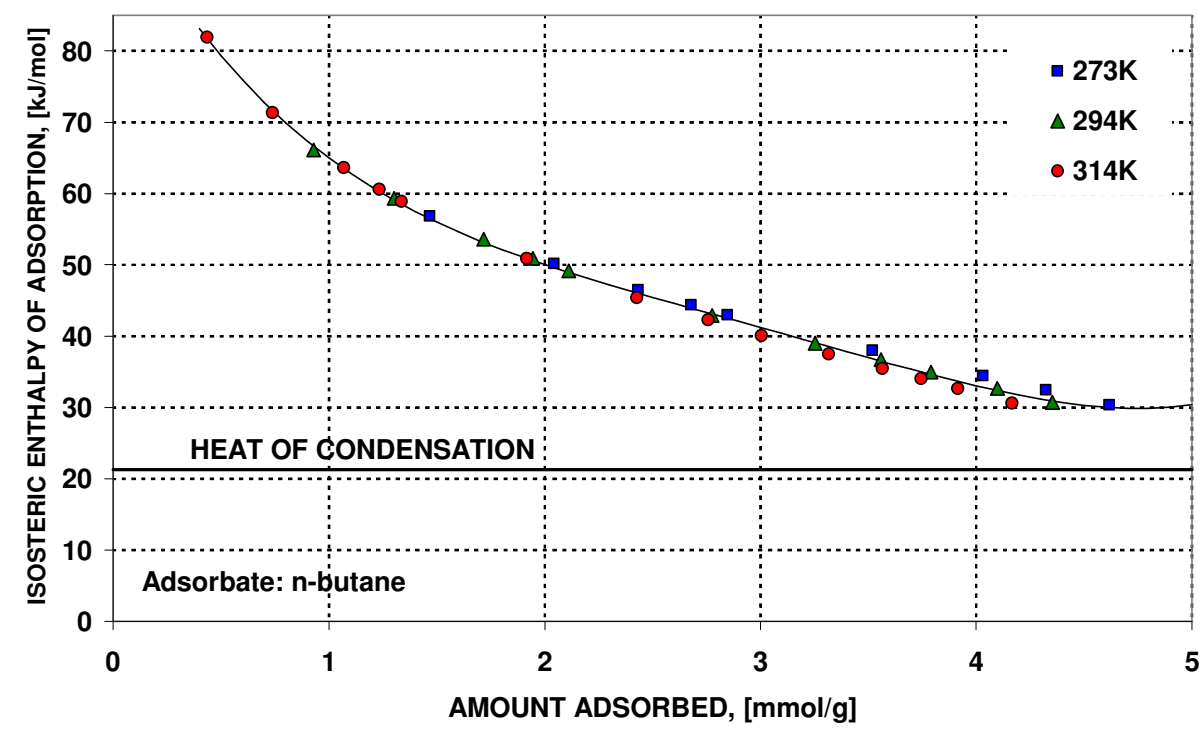

Fig. 4. Isosteric enthalpy of butane adsorption vs. amount adsorbed.

For system under study the isosteric heat of adsorption was higher than the heat of condensation and of the sufficient magnitude to be characterized as physical adsorption.

The approach proposed would be sufficient for numerical calculations of the thermodynamics of adsorption in the activated carbonbutane systems in wide range of temperatures and pressures and the simplicity of the procedures allows rapid screening of many active carbon types in different conditions facilitating and speeding up calculation for different conditions.

\section{CONCLUSIONS}

Adsorption potential theory successfully describes the adsorption equilibria of butane on active carbon. A generalized characteristic curve gives a possibility for successful prediction of adsorption equilibria for different gases. Only one adsorption isotherm is practically necessary to obtain the characteristic curve and this is sufficient to describe the adsorption at all other temperatures and pressures. The results can be used for the design of adsorption systems and for predicting adsorption equilibrium behavior of binary and/or multicomponent gaseous mixtures on active carbon under wide range of conditions, without time consuming and expensive experimental determination. 


\section{ACKNOWLEDGEMENTS}

The authors ${ }^{1}$ are grateful to the AGH - University of Science and Technology (Project 11.11.210.244) for its financial support of this work.

\section{REFERENCES}

[1] H. Marsch and F. Rodrigues-Reinosso, Activated Carbon, Elsevier Science \& Technology Books, UK, 2006.

[2] M. L. Terranova, S. Orlanducci and M. Rossi (Eds), Carbon Nanomaterials for Gas Adsorption, Taylor \& Francis Group, 2012.

[3] T. Bandosz (Ed.), Activated Carbon Surfaces in Environmental Remediation, Elsevier Ltd., UK, 2006.

[4] T. E. Rufford, D. Hulicova-Jurcakova and J. ZhuGreen, Carbon Materials - Advances and Applications, Taylor \& Francis Group, 2013.

[5] T. D. Burchell (Ed.), Carbon Materials for Advanced Technologies, Elsevier Ltd., UK, 1999.

[6] F. Cecen and O. Aktas, Activated Carbon for Water and Wastewater Treatment, WILEY-VCH Verlag GmbH \& Co. KGaA, Germany, 2012.

[7] Z. K. Chowdhury, R. S. Summers, G. P. Westerhoff, B. J. Leto, K. O. Nowack and C. J. Corwin, Activated Carbon: Solutions for Improving Water Quality, American Water Works Association, USA, 2013.

[8] Ruzhu Wang, Liwei Wang and Jingyi Wu, Adsorption refrigeration technology: theory and application, John Wiley \& Sons Singapore Pte. Ltd., 2014.

[9] F. Béguin and E. Frąckowiak (Eds.), Carbons for Electrochemical Energy Storage and Conversion Systems, Taylor and Francis Group, USA, 2010.

[10] D. D. Do, Adsorption Analysis: Equilibria and Kinetics, Imperial College Press, UK, 1998.

[11] G. O. Wood, Carbon, 39, 343, (2001).

[12] M. M. Dubinin, Progress in Surface and Membrane Science, Academic Press, New York, 9, 1, (1975).

[13] M. M. Dubinin, Carbon, 27, 457, (1989).

[14] S. Sircar and R. Mohr, C. Ristic, and M. B. Rao, Journal of Physical Chemistry B, 103, 6539, (1999).

[15] D. Ramirez., S. Qi, M. J. Rood and K. J. Hay, Environmental Science and Technology, 39, 5864, (2005).

[16] J. Jagiełło, C. O. Ania, J. B. Parra and C. Cook, Carbon, 91, 330, (2015). 